\title{
Influence Of Unusual Economic Conditions On The Occurrence Of The Size Anomaly
}

Charles E. Mossman, University of Manitoba, Canada Sergiy Rakhmayil, Ryerson University, Canada

\begin{abstract}
Much of the explanation for the size anomaly has been assigned to taxation and behavioural issues near the end of the calendar year. However, factor models based on company characteristics suggest that some type of risk may also have a long term effect on returns. We use a traditional multifactor model to re-examine the influence of macroeconomic variables on the magnitude and direction of size portfolio returns using traditional and Logit regression models. Our results indicate significant differences in sensitivity of returns to the market risk factor across size portfolios, but limited mean return effects of economic and financial factors. However, we find that macroeconomic factors that take on unusually extreme values influence the probable direction of annual size anomalies. The unusual economic conditions may influence investor riskreturn expectations differentially across size portfolios. These differing expectations are reflected in the occurrence of a size anomaly.
\end{abstract}

Keywords: size effect, stock returns, macroeconomic risks

\section{INTRODUCTION}

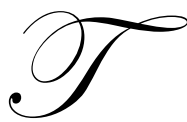

he existence of the size anomaly has puzzled academics since its appearance in the research of Banz (1981) and Reinganum $(1981,1983)$. Various explanations of this anomaly have been proposed, including year-end behavioral activities, such as tax-based selling, portfolio rebalancing, window dressing, and holiday neglect effects, as well as more traditional economic changes in systematic risk. Initial studies, such as Banz (1981), Reinganum (1983) and Chan, Chen, and Hsieh (1983) document a positive size effect, while more recent papers, such as Dimson and Marsh (1999), Olson et al (2002), Al-Rjoub et al (2005), find it negative or nonexistent. The apparent reversal or disappearance of the effect of the anomaly, on average, from about the mid1980's is a further puzzle, although its reversal in some years had been known since Brown, Kleidon and Marsh (1983). Our study concentrates on the longer term portion of the size anomaly which may be reflected in economic or market risk, rather than on rational or irrational behaviour of investors or portfolio managers over the calendar year-end or early in the new year.

Inclusion of size in cross sectional and time series factors such as those of Fama and French (1992) suggest that it may be influenced by the state of the economy. Small firms may have greater production flexibility than large firms, but are also less diversified in operations and have different capital structures. Small firm debt has a shorter average maturity that that of large firms, suggesting a greater exposure to changing credit conditions. Hence changes in economic conditions may affect firms of various sizes differently, and may result in very large or small (or negative) differences between portfolio returns of small and large firms.

The potential existence of return factors beyond the market influence has been explored since shortly after the Capital Asset Pricing Model (Sharpe, 1964) was developed. Chan, Chen, and Hsieh (1985) conducted crosssectional tests on the differences in market model residuals across size. In the context of the Capital Asset Pricing Model, their focus was on examining residual risk after a market factor had been eliminated. Research including Chan and Chen (1988), and more recent papers by Al-Rjoub et al (2005) and Theriou et al (2005) found crosssectional variation in returns, market betas, and other risk parameters. Implicitly, the empirical research of Fama and French (1995) acknowledges differences in the return characteristics of small firms by forming explanatory return 
portfolios based on size differentials as independent risk factors in addition to book to market effects and the market factor.

Other research has examined the direct effects of macroeconomic variables on stock returns. Early papers with this focus were Chan, Chen, and Hsieh (1983) and Chen, Roll, and Ross (1986), which selected various economic, industry and financial inputs. Research including Seyhun (1993), Kramer (1994), and Beller and Nofsinger (1998) have explored the effects of economic risk on size portfolio returns with mixed results. Chen and Zheng (1998) explore this question in international markets by using three independent variables across several countries. Although they estimated various statistics for portfolios, they did not provide direct statistical tests across size portfolios.

In a recent paper, Hahn, O'Neil, and Reyes (2004) study returns of size portfolios, as well as several different value portfolios, using a six-factor model based on macroeconomic variables. Eckbo, Masulis, and Norli (2000) developed this model, similar to that of Chen, Roll, and Ross (1986), to examine underperformance of seasoned equity offerings. The model uses several independent variables related to default risk, term structure, consumption, unanticipated inflation, and short-term interest rate structure, as well as the value-weighted market portfolio excess return. Hahn, O'Neil and Reyes measure the residual size anomaly with Jensen's alpha after regression of excess size portfolios on these independent variables. Since they generally find no statistically significant remaining abnormal returns (Jensen's alpha) related to size, they conclude that their macroeconomic and financial variables account for all size anomaly effects not explained in Fama and French's (1995) empirical model. This conclusion is valid for the average size anomaly, but still leaves the question of whether large individual year differences between small and large firm returns might be explained through changes in macroeconomic factors over time.

In this paper we re-examine how different size anomaly effects are related to levels of economic factors. We create market model equal-weighted index return residuals for each of ten size portfolios and regress them on the macroeconomic variables identified by Chen, Roll, and Ross (1986). Our focus is on residual economic risks in returns after removal of market risk, rather than the average effect given by Jensen's alpha.

Consistent with prior research on the size effect, including Chan and Chen (1988), Bhardwaj and Brooks (1993), Chan, Chen, and Hsieh (1985), Cho and Taylor (1987), Chan and Chen (1991), Athanassakos (1992), Cheung and Ng (1992), Mei (1993), and Kramer (1994), we find that small firms have significantly higher market risk and different economic risk exposure than large firms. Our economic factors do not have a strong effect on the mean magnitude of the size anomaly, although they do influence returns across the whole size portfolio range. Empirical results demonstrate that combinations of a change in expected inflation, unexpected inflation, default risk premium, term premium, and an oil and gas price index seem to influence the direction of the annual anomaly (positive or negative).

We then directly consider the effect of macroeconomic risk factors on the likelihood of an exceptionally large or small (reverse) size effect. Bae, Karolyi, and Stulz (2003) use an ordered Logit method to examine extreme foreign exchange transactions of a similar nature. We apply this method to annual size portfolio stock returns. Our results suggest that although the market factor is the most important in determining the magnitude of the size anomaly, some of the economic factors help to explain the probability of a very large size anomaly or the reversal of this anomaly for a given year.

In this paper, the next section provides a description of the data and summary of our method. The third section provides time series analysis of the stock returns and examines the plausibility of the risk explanation for the anomaly using macroeconomic factors. In the fourth section, discrete choice analysis examines the relationship of the direction of the size effect to macroeconomic risk factors. The final section concludes with a summary of results and observations for the direction of future research. 


\section{DATA AND METHOD}

The initial data for our time series analysis includes the stock market monthly equal weighted index return $(E W)$ of NYSE/AMEX/NASDAQ stocks from the CRSP database as the independent market risk variable. ${ }^{1}$ The dependent variables consisted of monthly portfolio returns constructed from ten CRSP size deciles. The first return series $(P M 1)$ was selected from the smallest stocks and the last return series (PM10) represented the largest stocks. The period of this study was from January 1960 to December $2005 .^{2}$

Table 1 demonstrates the characteristics of the monthly portfolio returns. As expected, the smallest portfolio (PM1) shows a mean return of 0.0157 , higher than the others, but there does not appear to be a huge difference across the other portfolios. The return standard deviation of PM1, 0.0776, is also higher than that of the other portfolios. Note that standard deviation declines monotonically with firm size.

We use US macroeconomic data in subsequent tests. We obtained US monthly industrial production ${ }^{3}$ (IP), 1-monthTreasury bill yields (TB), Treasury long-term bond yields (LGB), and Moody's Baa-rated corporate bond yields (Baa) from the Board of Governors of the Federal Reserve System website. ${ }^{4}$ The monthly consumer price index (CPI) and monthly producer price index, all commodities (PPI) originated from the Bureau of Labour Statistics. ${ }^{5}$ Finally, the monthly series of the West Texas intermediate crude oil price (OP) was from the Financial Forecast Center website. ${ }^{6}$

Using the procedures outlined by Chen, Roll, and Ross (1986), we constructed derived series as follows: monthly growth of industrial production, $M P_{t}=\ln \left(I P_{t} / I P_{t-1}\right)$, inflation, $I_{t}=\ln \left(C P I_{t} / C P I_{t-1}\right)$, term structure, $U T S_{t}=L G B_{t}-T B_{t-1}$, credit risk premium, $U P R=B a a_{t}-L G B_{t}$, and oil price variable, $O G_{t}=\left(O P_{t} / P P I_{t}\right)$. In addition, we used the procedure "Interest rate model", outlined in Fama and Gibbons (1984), to derive expected inflation $E_{t-1}\left[I_{t}\right]$ from inflation rates and T-bill yields. Using this estimate of the expected inflation, we constructed two more series: unexpected inflation $U I_{t}=I_{t}-E_{t-1}\left[I_{t}\right]$ and change in expected inflation $D E I_{t}=E_{t}\left[I_{t+1}\right]-E_{t-1}\left[I_{t}\right]$.

We adjusted the data for the first five factors as deviations from their corresponding means, consistent with Ross (1976). Also, following Kramer (1994), we introduced the stock market factor MKTREZ as OLS residuals (hence also with mean zero) by regressing $E W$ on MP, DEI, UI, UPR, and UTS.

The conditional number test (Greene, 2000, p. 258) in a time series regression of PM1, PM2,..,PM10 on $M P, D E I, U I, U P R, U T S$, and OG strongly suggested that the data were subject to a multicollinearity problem. First, the square root of the ratio of the largest to the smallest eigen value of the $\mathbf{X}^{\prime} \mathbf{X}$ matrix in the regressions was 83.74, which indicates multicollinearity. Second, introduction of OG into the regression with five factors decreases $\mathrm{t}$-values for the intercept term, URP, and UTS. To mitigate this, we orthogonalized the $O G$ factor by regressing it on the five factors. The residuals from this regression, OGREZ, were used in the multifactor model of the stock returns.

\footnotetext{
${ }^{1}$ The equal-weighted index was used for consistency with earlier studies, such as Chen, Roll, and Ross (1986). Its use will tend to decrease the size anomaly, compared to using the value-weighted index. However, tests using the value-weighted index similar to Hahn, O'Neil, and Reyes (2004) gave consistent results.

2 The availability of some of our variable data limited this study to the period indicated.

${ }^{3}$ These variables are not seasonally adjusted, and hence capture any seasonal effects.

${ }^{4}$ The government long term bond yield is the "Market yield on U.S. Treasury securities at 10-year constant maturity", quoted on investment basis from the Federal Reserve web site. (Its Federal Reserve data identifier is H15/H15/RIFLGFCY10_N.M.). This series, as well as all the other data from the Federal Reserve system were downloaded from http://www.federalreserve.gov

${ }^{5}$ http://www.bls.gov

${ }^{6} \underline{\text { http://www.forecasts.org }}$
} 
In summary, the series of economic factors used in the analysis included monthly growth of industrial production (MP), change in expected inflation (DEI), unexpected inflation (UI), the credit risk premium (UPR), the interest rate term structure (UTS), the market return residual (MKTREZ), and the oil and gas price change residual (OGREZ). These factors are the same as those used in Chen, Roll and Ross (1986).

Statistical characteristics of the economic variables are presented in Table 2. Note that the least volatile factor is the term premium UTS, with corresponding standard deviation of 0.0010 , followed by a slightly more volatile credit risk premium UPR, with corresponding standard deviation of 0.0014 . Also, the most volatile variable is the oil price factor OG; its standard deviation is almost four times the standard deviation of the stock market factor. ${ }^{7}$

Our empirical tests initially demonstrate the size anomaly and its relationship to market and macroeconomic risk variables using time-series size portfolios of CRSP monthly returns. We check the residuals of these regressions for significant differences between small and large firm returns following risk-adjustment. This method of testing return differences is similar to that of Keim (1983). ${ }^{8}$

\section{EMPIRICAL TESTS AND RESULTS}

\section{Size Relationships to Market and Macroeconomic Variables}

We first demonstrate the historical existence and "disappearance" of the small firm anomaly. Figure 1 demonstrates the annual difference between the portfolio returns for smallest and the largest size deciles, then adjusts for the market portfolio, as discussed below. The figure shows that before 1980, average small firm returns outperformed those for large firms. However, since the mid-1980s, small firm returns appear not to have exceeded large firm returns on average, but do tend to be more extreme. Unadjusted for risk differences, the small firm portfolio seems to exaggerate market cycles. These return differences could relate to small firm higher sensitivity to market or other risk factors on average or only when those factors take on unusual values.

Some researchers have argued that size-related anomalies result from risk mismeasurement introduced by the CAPM by using only the market return as the single risk factor (e.g., Berk, 1995). We generate abnormal returns for size portfolios and examine the direction of the size anomaly in each month. First, we estimate the market model $^{9}$ and save the residuals.

$$
\mathrm{PM}_{\mathrm{i}, \mathrm{t}}=\beta_{0, \mathrm{i}}+\beta_{1, \mathrm{i}} \mathrm{EW}_{\mathrm{t}}+\varepsilon_{\mathrm{i}, \mathrm{t}}, \mathrm{i}=1,2, \ldots, 10
$$

where $\mathrm{PM}_{\mathrm{i}, \mathrm{t}}$ is the month $\mathrm{t}$ return on portfolio $\mathrm{i}$ and $\mathrm{EW}_{\mathrm{t}}$ is the month $\mathrm{t}$ equal-weighed market index return.

For a one-factor market model, the model residuals can be interpreted as abnormal returns, because the predicted values of the portfolio returns are expectations of the portfolio returns conditional on the market return, i.e.

$\hat{\beta}_{0, i}+\hat{\beta}_{1, i} E W_{t}=E\left[P M_{i, t} \mid E W_{t}\right]$

\footnotetext{
${ }^{7}$ The effects using OG or OGREZ were similar.

${ }^{8}$ Using simulation, Nelson and Kim (1993) express a concern that there could be small sample bias in prediction regressions. This bias is a "decreasing function of the sample size and an increasing function of the autocorrelation in the predictor and of the contemporaneous correlation between innovations in the two variables." Nelson and Kim (1993) suggest that simulations might be needed to determine the actual distribution of the t-statistic under these circumstances. Despite this suggestion, it does not appear that other recent authors have included simulations in their prediction estimates (see for example Ferson and Harvey (1999), Moskowitz (2003), Goyal and Santa-Clara (2003), Bekaert et al (2009)). Although we do not use simulation to estimate bias in t-statistics, we mitigate this concern by estimating the relationship using SUR, which adjusts for situations where the errors are heteroskedastic and contemporaneously correlated, and use a fairly long estimation period as suggested by Nelson and Kim (1993). This should control for the bias problem under the circumstances they believe might exist.

${ }^{9}$ Although we use the EW index as a market proxy, the value-weighted indices produced similar results.
} 


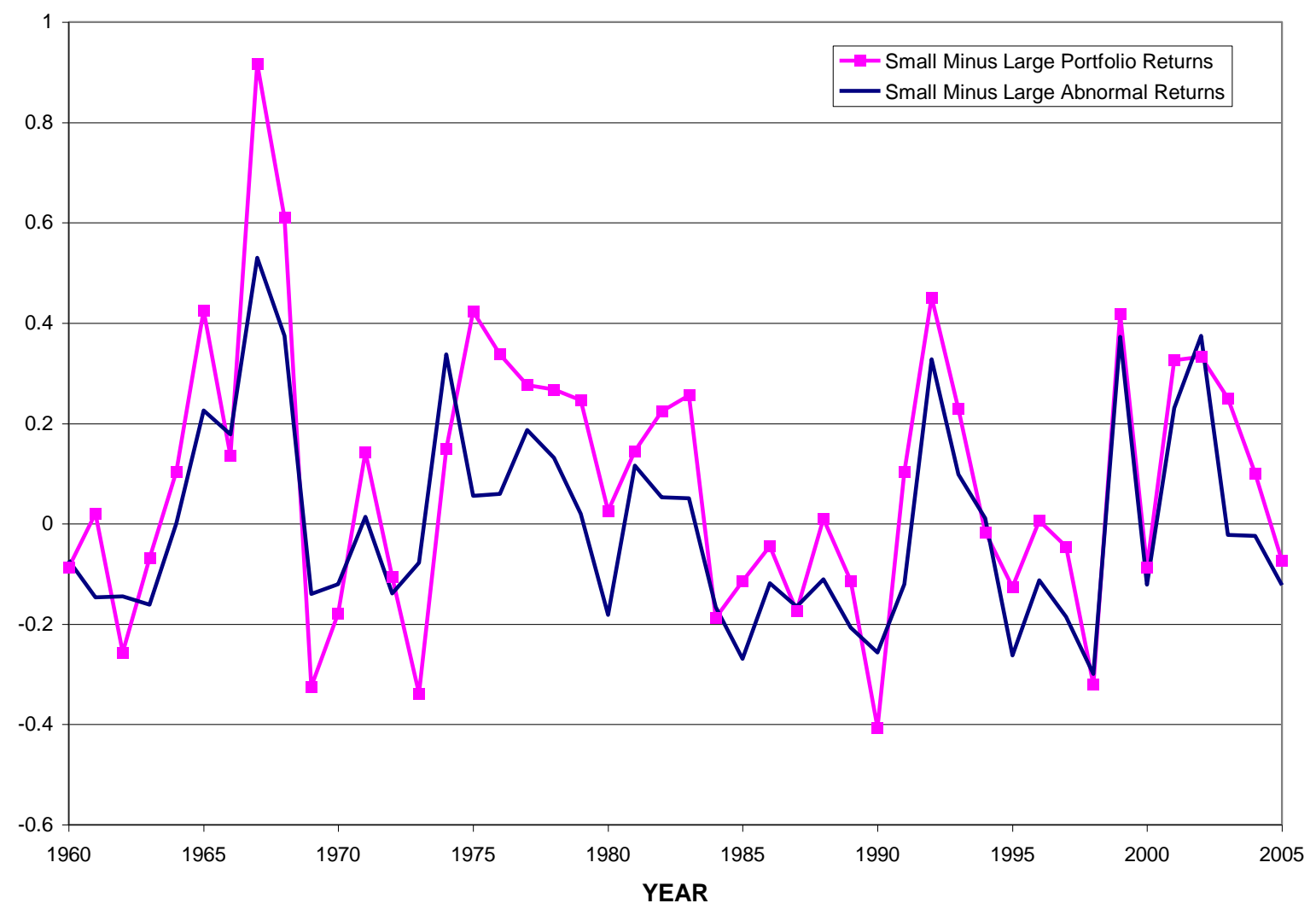

Figure 1.

Difference between the smallest and the largest size decile annual portfolio total returns, and difference between the smallest and the largest size decile portfolio annual abnormal returns (generated by a market model) for each year over the period 1960-2005.

We present the estimation results for all size portfolios for equation 1 in Table 3. Both the market and riskadjusted returns show that our abnormal returns are consistent with those obtained by previous researchers. The difference between market-adjusted returns of the smallest and the largest portfolio in relative terms is much larger than the difference in the estimated beta coefficients. ${ }^{10}$

In order to determine whether sensitivities to the market risk differ across portfolios, we estimate equation (1) using SUR and conduct Wald chi-square tests of the equivalence of the coefficients between the smallest size portfolio and each of the other nine size portfolios. Test results in Table 3 demonstrate that all sensitivities to the market risk factor are significantly different at $1 \%$ level. For example the Chi-Square statistic of whether $\beta_{1,1}=\beta_{1,4}$, the equivalence of betas in portfolio 1 and 4 , equals 54.6279 and is highly significant. Similarly, Figure 1 shows that both the small firm returns and the "abnormal" small firm portfolio returns, adjusted for market risk, still demonstrate the same patterns compared to the large firm portfolio returns. Thus, market risk alone does not explain the higher shifts in small firm returns during the business cycle.

Next we explore whether adding economic variables to the model can explain more of the variation, using a time series multifactor model (as described, for example, in Campbell, Lo, and MacKinlay, 1997, p. 226). We examine whether introducing economic factors into the regressions affects significance of the market factor.

\footnotetext{
${ }^{10}$ The relative difference between the mean market adjusted returns as a ratio of the larger return is $(0.0040-(-0.0030)) / 0.0040=1.75$. The ratio of the difference in market betas is $(1.2678-0.6102) / 1.2678=0.5187$.
} 
We estimate a portfolio least squares regressions of the form ${ }^{11}$ :

$$
\begin{aligned}
P M_{i, t}=\gamma_{0, i}+\gamma_{1, i} M P_{t} & +\gamma_{2, i} D E I_{t}+\gamma_{3, i} U I_{t}+ \\
& +\gamma_{4, i} U P R+\gamma_{5, i} U T S+\gamma_{6, i} M K T R E Z+\gamma_{7, i} O G R E Z \\
& i=1,2, \ldots, 10 .
\end{aligned}
$$

In these regressions for each portfolio, systematic return variation from economic factors may be captured by the market portfolio, since its residual from regression on the economic factors is used. ${ }^{12}$ If all economic factors had insignificant regression coefficients, it would suggest that the economic factors and market portfolio returns carry the same information in explaining portfolio returns.

Estimation results, presented in Table 4, suggest that in addition to the market portfolio, macroeconomic variables help to explain the returns within size portfolios. ${ }^{13}$ For example, the portfolio 10 return has estimated sensitivity 7.2457 to default risk premium variable UPR, with a corresponding t-value of 2.2408 , which suggests that this risk factor significantly affects pricing of the largest portfolio returns. Consistent with previous studies and theory, estimated sensitivities to the market risk are all positive and significant, and are close to the market betas presented in Table 3.

Although Table 4 demonstrates that portfolio returns include some residual variation due to macroeconomic factors, the total variation explained for each portfolio is very close to that in the market model. Most of the macroeconomic effects on returns are reflected in the market portfolio return. Moreover, tests of the difference between small and large firm portfolio returns (results not shown) and a Wald test of the differences of portfolio coefficients for each factor (in the last two rows of Table 4) reveal that the coefficients for size portfolios are not significantly different. Thus, the average size anomaly is not explained by the variation in the macroeconomic factors.

\section{Further Tests of the Annual the Size Anomaly and Macroeconomic Variables}

Our macroeconomic factors do not explain the average size anomaly, since their coefficients are not significantly different for various size portfolios. However, Figure 1 shows that there are large magnitude shifts in the anomaly even after taking account of the market factor. Although the size effect averages a smaller amount in recent years compared to before 1980, it is quite variable by year even in recent years and often reverses. Dimson and Marsh (1999) claim that "Murphy's law" holds in relation to these reversals. However, we wish to determine if macroeconomic factors have an influence on the probability and direction of the anomaly. Therefore we investigate the likelihood of observing very large positive or a negative size effect in a given year.

\footnotetext{
${ }^{11}$ Coefficient estimates are exactly the same as from ten separate OLS regressions. However, using the SUR estimator allows for easy testing of differing size portfolio factor sensitivity.

${ }^{12}$ MKTREZ is a residual series from the regression of EW on the Chen, Roll, and Ross (1976) macroeconomic variables. We orthogonalize the market return with respect to the economic factors under the assumption that the economic factors may explain some of the variability in the stock market index.

${ }^{13}$ Chan and Chen (1988, p.323) argued that the equally weighted index is a better proxy for a market portfolio than the valueweighted index. However, the equations were also estimated using excess returns and with value-weighted and equal-weighted market portfolios. Results were essentially the same under all four alternatives. The results with total returns and an equalweighted portfolio are shown for comparability with Chen, Roll and Ross (1986), and since using an equal-weighted portfolio tends to minimize significance of empirical results for small firms.
} 
Table 1. Statistical parameters and correlations of the stock market variables

\begin{tabular}{|c|c|c|c|c|c|c|c|c|c|c|c|}
\hline & PM1 & PM2 & PM3 & PM4 & PM5 & PM6 & PM7 & PM8 & PM9 & PM10 & EW \\
\hline Mean & 0.0157 & 0.0132 & 0.0120 & 0.0119 & 0.0112 & 0.0118 & 0.0116 & 0.0107 & 0.0109 & 0.0087 & 0.0117 \\
\hline Median & 0.0086 & 0.0120 & 0.0134 & 0.0132 & 0.0112 & 0.0141 & 0.0150 & 0.0121 & 0.0135 & 0.0098 & 0.0118 \\
\hline Maximum & 0.5348 & 0.4620 & 0.3979 & 0.3719 & 0.3352 & 0.3172 & 0.2504 & 0.2470 & 0.2167 & 0.1765 & 0.3318 \\
\hline Minimum & -0.3067 & -0.3010 & -0.2979 & -0.2934 & -0.2908 & -0.2802 & -0.2720 & -0.2626 & -0.2483 & -0.1992 & -0.2680 \\
\hline Std. Dev. & 0.0776 & 0.0657 & 0.0596 & 0.0570 & 0.0557 & 0.0538 & 0.0515 & 0.0484 & 0.0470 & 0.0412 & 0.0532 \\
\hline Obs & 552 & 552 & 552 & 552 & 552 & 552 & 552 & 552 & 552 & 552 & 552 \\
\hline \multicolumn{12}{|c|}{ Sample correlations } \\
\hline PM1 & 1.0000 & & & & & & & & & & \\
\hline PM2 & 0.9383 & 1.0000 & & & & & & & & & \\
\hline PM3 & 0.9000 & 0.9626 & 1.0000 & & & & & & & & \\
\hline PM4 & 0.8728 & 0.9506 & 0.9772 & 1.0000 & & & & & & & \\
\hline PM5 & 0.8441 & 0.9308 & 0.9650 & 0.9797 & 1.0000 & & & & & & \\
\hline PM6 & 0.8081 & 0.9008 & 0.9415 & 0.9627 & 0.9794 & 1.0000 & & & & & \\
\hline PM7 & 0.7589 & 0.8636 & 0.9123 & 0.9403 & 0.9617 & 0.9812 & 1.0000 & & & & \\
\hline PM8 & 0.7108 & 0.8225 & 0.8771 & 0.9097 & 0.9370 & 0.9629 & 0.9772 & 1.0000 & & & \\
\hline PM9 & 0.6539 & 0.7719 & 0.8291 & 0.8657 & 0.8966 & 0.9315 & 0.9578 & 0.9785 & 1.0000 & & \\
\hline PM10 & 0.5048 & 0.6248 & 0.6817 & 0.7177 & 0.7536 & 0.7968 & 0.8354 & 0.8758 & 0.9174 & 1.0000 & \\
\hline EW & 0.8696 & 0.9467 & 0.9679 & 0.9790 & 0.9818 & 0.9779 & 0.9661 & 0.9478 & 0.9173 & 0.7891 & 1.0000 \\
\hline
\end{tabular}


Table 2. Statistical parameters and correlations of the economic variables.

Description of independent variables: $P M_{i, t}$ - monthly return on portfolio $i$ at time $t ; M P_{t}$ - monthly growth rate of industrial production; $D E I_{t}-$ change in expected inflation; $U I_{t}$ - unexpected inflation; $U P R_{t}$ - default risk premium; $U T S_{t}$ - term structure premium; $M K T R E{ }_{t}$ - NYSE/AMEX/NASDAQ market return, orthogonalized with respect to first five factors; $O G R E Z_{t}$ - oil price variables, orthogonalized with respect to first five factors.

\begin{tabular}{|c|c|c|c|c|c|c|c|}
\hline & MP & DEI & UI & UPR & UTS & MKTREZ & OGREZ \\
\hline Mean & 0.0000 & 0.0000 & -0.0012 & 0.0000 & 0.0000 & 0.0000 & 0.0000 \\
\hline Median & 0.0018 & -0.0001 & -0.0012 & -0.0001 & 0.0000 & 0.0013 & -0.0210 \\
\hline Maximum & 0.0511 & 0.0165 & 0.0139 & 0.0037 & 0.0025 & 0.0527 & 0.2751 \\
\hline Minimum & -0.0711 & -0.0156 & -0.0204 & -0.0033 & -0.0034 & -0.0741 & -0.2274 \\
\hline Std. Dev. & 0.0230 & 0.0029 & 0.0042 & 0.0014 & 0.0010 & 0.0227 & 0.0784 \\
\hline Obs & 552 & 552 & 552 & 552 & 552 & 552 & 552 \\
\hline \multicolumn{8}{|c|}{ Sample correlations } \\
\hline $\mathrm{MP}$ & 1.0000 & & & & & & \\
\hline DEI & 0.0829 & 1.0000 & & & & & \\
\hline UI & 0.0058 & -0.4571 & 1.0000 & & & & \\
\hline UPR & -0.0187 & -0.0196 & -0.0300 & 1.0000 & & & \\
\hline UTS & 0.0314 & -0.0170 & 0.0105 & 0.9275 & 1.0000 & & \\
\hline MKTREZ & 0.9873 & 0.0000 & 0.0000 & 0.0000 & 0.0000 & 1.0000 & \\
\hline OGREZ & 0.0000 & 0.0000 & 0.0000 & 0.0000 & 0.0000 & 0.0000 & 1.0000 \\
\hline
\end{tabular}


Table 3. Estimation results for the market model (equation 1) and test of equality in market betas.

$\mathrm{PM}_{\mathrm{i}, \mathrm{t}}=\beta_{0, \mathrm{i}}+\beta_{1, \mathrm{i}} \mathrm{EW}_{\mathrm{t}}+\varepsilon_{\mathrm{i}, \mathrm{t}}, \mathrm{i}=1,2, \ldots, 10$, and mean market-adjusted returns for each size portfolio, $\overline{P M}_{i}-\overline{E W}_{\text {. }}$

\begin{tabular}{|c|c|c|c|c|c|c|c|}
\hline Decile, $i$ & $\overline{P M}_{i}-\overline{E W}$ & Intercept & EW & $\overline{\boldsymbol{R}}^{2}$ & DW-statistic & Degr. of freedom & $\begin{array}{l}\text { Wald Test of equality in betas across } \\
\text { sizes }\end{array}$ \\
\hline Smallest & 0.0040 & $\begin{array}{c}0.0009 \\
(0.5111)\end{array}$ & $\begin{array}{c}1.2678 \\
(41.3077)\end{array}$ & 0.7558 & 1.9589 & $2: 552$ & \\
\hline 2 & 0.0015 & $\begin{array}{c}-0.0005 \\
(-0.5486)\end{array}$ & $\begin{array}{c}1.1673 \\
(68.9142)\end{array}$ & 0.8960 & 1.9650 & $2: 552$ & $\begin{array}{l}21.1427 \\
(0.0000)\end{array}$ \\
\hline 3 & 0.0003 & $\begin{array}{c}-0.0007 \\
(-1.0711)\end{array}$ & $\begin{array}{c}1.0832 \\
(90.3324)\end{array}$ & 0.9367 & 2.0609 & $2: 552$ & $\begin{array}{l}48.3985 \\
(0.0000)\end{array}$ \\
\hline 4 & 0.0001 & $\begin{array}{c}-0.0004 \\
(-0.8515)\end{array}$ & $\begin{array}{c}1.0487 \\
(112.6698)\end{array}$ & 0.9584 & 2.0601 & $2: 552$ & $\begin{array}{l}54.6279 \\
(0.0000)\end{array}$ \\
\hline 5 & -0.0006 & $\begin{array}{c}-0.0009 \\
(-1.8642)\end{array}$ & $\begin{array}{c}1.0264 \\
(121.3753)\end{array}$ & 0.9639 & 2.0569 & $2: 552$ & $\begin{array}{l}55.9006 \\
(0.0000)\end{array}$ \\
\hline 6 & 0.0001 & $\begin{array}{c}0.0002 \\
(0.4368)\end{array}$ & $\begin{array}{c}0.9881 \\
(109.7245)\end{array}$ & 0.9562 & 2.1681 & $2: 552$ & $\begin{array}{l}63.8011 \\
(0.0000)\end{array}$ \\
\hline 7 & -0.0001 & $\begin{array}{c}0.0007 \\
(1.1393)\end{array}$ & $\begin{array}{c}0.9336 \\
(87.7845)\end{array}$ & 0.9333 & 2.0625 & $2: 552$ & $\begin{array}{l}77.1977 \\
(0.0000)\end{array}$ \\
\hline 8 & -0.0010 & $\begin{array}{c}0.0006 \\
(0.8922)\end{array}$ & $\begin{array}{c}0.8620 \\
(69.7186)\end{array}$ & 0.8982 & 2.1328 & $2: 552$ & $\begin{array}{c}101.9127 \\
(0.0000)\end{array}$ \\
\hline 9 & -0.0009 & $\begin{array}{c}0.0014 \\
(1.6627)\end{array}$ & $\begin{array}{c}0.8099 \\
(54.0107)\end{array}$ & 0.8411 & 2.0630 & $2: 552$ & $\begin{array}{c}114.2136 \\
(0.0000)\end{array}$ \\
\hline Largest & -0.0030 & $\begin{array}{c}0.0016 \\
(1.4245) \\
\end{array}$ & $\begin{array}{c}0.6102 \\
(30.1319) \\
\end{array}$ & 0.6221 & 2.1162 & $2: 552$ & $\begin{array}{c}204.4176 \\
(0.0000) \\
\end{array}$ \\
\hline
\end{tabular}

Notes: Equation (1) estimates are obtained using least squares regressions. Numbers in parentheses are t-values that correspond to the estimated coefficients. The Wald test for equality is calculated for differences between betas of the smallest decile firms and each of the other deciles as follows: We estimate equation (1) simultaneously for all ten portfolios using the seemingly unrelated equations (SUR) method and conduct direct tests of $\beta_{1}=\beta_{\mathrm{j}}, \mathrm{j}=2, \ldots, 10$. Coefficient equality test statistics are Chi-Squared values; numbers in parentheses are corresponding p-values. 
Table 4. Estimation output of equation 3 using the least squares method, January 1960 - December 2005.

The model: $P M_{i, t}=\gamma_{0, i}+\gamma_{1, i} M P_{t}+\gamma_{2, i} D E I_{t}+\gamma_{3, i} U I_{t}+\gamma_{4, i} U P R+\gamma_{5, i} U T S+\gamma_{6, i} M K T R E Z+\gamma_{7, i} O G R E Z, i=1,2, \ldots, 10$. Description of variables: $P M_{i, t}$ - monthly return on portfolio $i$ at time $t ; M P_{t}$ - monthly growth rate of industrial production; $D E I_{t}$ - change in expected inflation; $U I_{t}$ - unexpected inflation;

$U P R_{t}$ - risk premium; $U T S_{t}$ - term structure variable; $M K T R E Z_{t}$ - NYSE/AMEX/NASDAQ market return, orthogonalized with respect to first five factors; $O G R E Z_{t}-$ oil price variables, orthogonalized with respect to first five factors. Equality across sizes is Chi Square statistic for Wald test with the null hypothesis that a certain coefficient is

\begin{tabular}{|c|c|c|c|c|c|c|c|c|c|c|}
\hline Size, $i$ & $\hat{\gamma}_{0, i}$ & $M P_{t}$ & $D E I_{t}$ & $U I_{t}$ & $U P R_{t}$ & $U T S_{t}$ & $M_{K T R E Z}$ & OGREZ ${ }_{t}$ & $\overline{\mathrm{R}}^{2}$ & DW \\
\hline Smallest & 0.0138 & 0.0144 & -1.3068 & -2.1714 & 11.7457 & 4.1543 & 1.2734 & -0.0126 & 0.7557 & 1.9840 \\
\hline t-stat & (7.9570) & $(0.2011)$ & $(-2.0712)$ & $(-4.8316)$ & $(2.3973)$ & $(2.5386)$ & $(40.6431)$ & $(-0.5359)$ & & \\
\hline 2 & 0.0114 & -0.0535 & -0.8300 & -1.8307 & 11.8932 & 3.8778 & 1.1723 & -0.0015 & 0.8959 & 1.9967 \\
\hline t-stat & (11.9860) & $(-1.3530)$ & $(-2.3832)$ & $(-7.3801)$ & (4.3978) & $(4.2931)$ & $(67.7850)$ & $(-0.1150)$ & & \\
\hline 3 & 0.0100 & -0.0609 & -0.8980 & -1.7453 & 15.5691 & 3.9768 & 1.0826 & 0.0114 & 0.9366 & 2.0646 \\
\hline t-stat & (14.7825) & $(-2.1710)$ & $(-3.6395)$ & $(-9.9305)$ & (8.1253) & $(6.2139)$ & (88.3492) & (1.2407) & & \\
\hline 4 & 0.0099 & -0.0566 & -0.7394 & -1.7520 & 13.8522 & 3.7835 & 1.0485 & 0.0081 & 0.9585 & 2.0786 \\
\hline t-stat & (18.9586) & $(-2.6064)$ & $(-3.8688)$ & $(-12.8709)$ & (9.3343) & (7.6331) & (110.4769) & (1.1350) & & \\
\hline 5 & 0.0094 & -0.1019 & -0.6845 & -1.6224 & 13.7362 & 3.5209 & 1.0270 & 0.0105 & 0.9641 & 2.0802 \\
\hline t-stat & (19.7121) & $(-5.1729)$ & $(-3.9477)$ & $(-13.1366)$ & (10.2017) & (7.8291) & (119.2667) & (1.6187) & & \\
\hline 6 & 0.0102 & -0.0946 & -0.4910 & -1.4024 & 13.8972 & 4.0169 & 0.9884 & 0.0131 & 0.9561 & 2.1985 \\
\hline t-stat & (20.0258) & $(-4.4935)$ & $(-2.6499)$ & $(-10.6248)$ & (9.6577) & (8.3577) & (107.4046) & (1.8895) & & \\
\hline 7 & 0.0100 & -0.0951 & -0.3254 & -1.3665 & 13.5432 & 3.7551 & 0.9326 & 0.0095 & 0.9330 & 2.0911 \\
\hline t-stat & (16.6711) & $(-3.8210)$ & $(-1.4858)$ & $(-8.7593)$ & (7.9629) & (6.6102) & $(85.7465)$ & (1.1642) & & \\
\hline 8 & 0.0093 & -0.0993 & -0.5643 & -1.2423 & 13.4652 & 3.8263 & 0.8593 & -0.0042 & 0.8976 & 2.1534 \\
\hline t-stat & (13.2602) & $(-3.4307)$ & $(-2.2153)$ & $(-6.8463)$ & (6.8067) & (5.7910) & (67.9267) & $(-0.4432)$ & & \\
\hline 9 & 0.0097 & -0.1293 & -0.2113 & -1.0614 & 11.9968 & 3.2779 & 0.8090 & -0.0047 & 0.8406 & 2.0901 \\
\hline t-stat & (11.4233) & $(-3.6887)$ & $(-0.6847)$ & $(-4.8286)$ & $(5.0059)$ & $(4.0951)$ & $(52.7854)$ & $(-0.4097)$ & & \\
\hline Largest & 0.0078 & -0.1212 & 0.1657 & -0.9049 & 7.2457 & 2.8631 & 0.6080 & -0.0179 & 0.6217 & 2.1283 \\
\hline t-stat & $(6.8684)$ & $(-2.5628)$ & $(0.3979)$ & $(-3.0508)$ & $(2.2408)$ & $(2.6510)$ & $(29.4031)$ & $(-1.1475)$ & & \\
\hline Equality across sizes & 20.4251 & 9.0844 & 10.6000 & 7.0845 & 10.6929 & 4.2810 & 382.2103 & 10.7913 & & \\
\hline p-value & $(0.0155)$ & $(0.4295)$ & $(0.3041)$ & $(0.6283)$ & $(0.2974)$ & $(0.8920)$ & $(0.0000)$ & $(0.2903)$ & & \\
\hline
\end{tabular}

Note: The number of observations is 552 . 
Table 5. Ranking of size effect by year over from 1960 to 2005

Annual difference between the smallest and the largest portfolio cumulative abnormal returns,

\begin{tabular}{|c|c|c|c|c|c|}
\hline YEAR & A1-A10 & Category & YEAR & A1-A10 & Category \\
\hline 1967 & 0.5301 & 3 & 1960 & -0.0733 & 2 \\
\hline 1968 & 0.3746 & 3 & 1973 & -0.0772 & 2 \\
\hline 2002 & 0.3746 & 3 & 1988 & -0.1108 & 2 \\
\hline 1999 & 0.3727 & 3 & 1996 & -0.1129 & 2 \\
\hline 1974 & 0.3381 & 3 & 1986 & -0.1183 & 2 \\
\hline 1992 & 0.3276 & 2 & 1970 & -0.1200 & 2 \\
\hline 2001 & 0.2303 & 2 & 1991 & -0.1203 & 2 \\
\hline 1965 & 0.2254 & 2 & 2000 & -0.1212 & 2 \\
\hline 1977 & 0.1871 & 2 & 2005 & -0.1229 & 2 \\
\hline 1966 & 0.1784 & 2 & 1972 & -0.1392 & 2 \\
\hline 1978 & 0.1318 & 2 & 1969 & -0.1396 & 2 \\
\hline 1981 & 0.1156 & 2 & 1962 & -0.1449 & 2 \\
\hline 1993 & 0.0986 & 2 & 1961 & -0.1468 & 2 \\
\hline 1976 & 0.0598 & 2 & 1963 & -0.1609 & 2 \\
\hline 1975 & 0.0554 & 2 & 1987 & -0.1649 & 2 \\
\hline 1982 & 0.0523 & 2 & 1984 & -0.1659 & 2 \\
\hline 1983 & 0.0505 & 2 & 1980 & -0.1816 & 2 \\
\hline 1979 & 0.0191 & 2 & 1997 & -0.1854 & 2 \\
\hline 1971 & 0.0141 & 2 & 1989 & -0.2066 & 1 \\
\hline 1994 & 0.0105 & 2 & 1990 & -0.2568 & 1 \\
\hline 1964 & 0.0010 & 2 & 1995 & -0.2626 & 1 \\
\hline 2003 & -0.0225 & 2 & 1985 & -0.2694 & 1 \\
\hline 2004 & -0.0238 & 2 & 1998 & -0.2996 & 1 \\
\hline
\end{tabular}


Table 6. Ordered logit model explaining abnormal returns

Estimates of the ability of macroeconomic and market explanatory variables to discriminate between unusually high or low abnormal returns and those within the narrower midreturn range, based on estimated probabilities of observations being in one of the three states. The low and high states represent the years with the $10 \%$ lowest and highest differences in returns between the small and large firm portfolios. The remaining years are placed in the middle state.

The ordered logit system of equations is:

$$
\begin{aligned}
& \ln \frac{p_{1}}{1-p_{1}}=\alpha_{1}+\delta_{1} M P_{t}+\delta_{2} D E I_{t}+\delta_{3} U I_{t}+\delta_{4} U P R_{t}+\delta_{5} U T S_{t}+\delta_{6} M_{K T R E Z_{t}}++\delta_{7} O_{G R E Z_{t}} \\
& \ln \frac{p_{1}+p_{2}}{1-p_{1}-p_{2}}=\alpha_{2}+\delta_{1} M P_{t}+\delta_{2} D E I_{t}+\delta_{3} U I_{t}+\delta_{4} U P R_{t}+\delta_{5} U T S_{t}++\delta_{6} M \text { TREZ }_{t}+\delta_{7} \text { OGREZ }_{t} \\
& \mathrm{p}_{1}+\mathrm{p}_{2}+\mathrm{p}_{3}=1 .
\end{aligned}
$$

\begin{tabular}{|c|c|c|c|c|c|c|}
\hline \multicolumn{7}{|c|}{ Logit estimates for ordered abnormal returns, all months } \\
\hline \multicolumn{7}{|c|}{ Standard } \\
\hline & \multicolumn{3}{|c|}{ Error } & \multicolumn{2}{|r|}{ LR Test of hypothesis } & \multirow[b]{2}{*}{ p-value } \\
\hline & Estimate & & Z-stats & Prob. & that "all slopes $=0$ " & \\
\hline$\alpha 1$ & -2.4593 & 0.1685 & -14.5911 & 0.0000 & 41.2297 & 0.0000 \\
\hline$\alpha 2$ & 2.0834 & 0.1296 & 16.0740 & 0.0000 & & \\
\hline MP & 0.3634 & 4.7162 & 0.0770 & 0.9386 & Akaike info criterion & 1.306458 \\
\hline DEI & 100.2510 & 33.9850 & 2.9499 & 0.0032 & Log likelihood & -351.583 \\
\hline UI & 136.7860 & 23.9670 & 5.7073 & 0.0000 & LR index (Pseudo-R2) & 0.055387 \\
\hline UPR & 493.1775 & 176.5330 & 2.7937 & 0.0052 & Included observations: & 552 \\
\hline UTS & -737.8583 & 240.1330 & -3.0727 & 0.0021 & & \\
\hline MKTREZ & 2.1972 & 1.9110 & 1.1498 & 0.2502 & & \\
\hline OGREZ & -4.2419 & 1.0580 & -4.0095 & 0.0001 & & \\
\hline
\end{tabular}


Table 7. Selected values of the probability distribution function for the size effect regime

The input values of the specified variables are used to "predict" the state ( $\mathrm{Y}_{\mathrm{i}}$ ) using the ordered logit model (5a-5c) by providing its "probability" (in sample). State 1 is a low (negative) abnormal size anomaly, state 2 is the $80 \%$ of size returns closer to the mean, and state 3 is high abnormal returns.

\begin{tabular}{|c|c|c|c|c|c|c|c|c|}
\hline Line & DEI & UI & UPR & UTS & OGREZ & $\operatorname{Prob}[Y t=1]$ & $\operatorname{Prob}[Y \mathrm{t}=2]$ & $\operatorname{Prob}[Y t=3]$ \\
\hline 1 & 0.0000 & 0.0000 & 0.0000 & 0.0000 & 0.0000 & 0.0788 & 0.8105 & 0.1107 \\
\hline 2 & 0.0139 & 0.0000 & 0.0000 & 0.0000 & 0.0000 & 0.0208 & 0.6452 & 0.3341 \\
\hline 3 & -0.0204 & 0.0000 & 0.0000 & 0.0000 & 0.0000 & 0.3979 & 0.5862 & 0.0159 \\
\hline 4 & 0.0000 & 0.0037 & 0.0000 & 0.0000 & 0.0000 & 0.0490 & 0.7798 & 0.1712 \\
\hline 5 & 0.0000 & -0.0033 & 0.0000 & 0.0000 & 0.0000 & 0.1184 & 0.8082 & 0.0735 \\
\hline 6 & 0.0000 & 0.0000 & 0.0025 & 0.0000 & 0.0000 & 0.0243 & 0.6763 & 0.2993 \\
\hline 7 & 0.0000 & 0.0000 & -0.0034 & 0.0000 & 0.0000 & 0.3138 & 0.6635 & 0.0227 \\
\hline 8 & 0.0000 & 0.0000 & 0.0000 & 0.0527 & 0.0000 & 1.0000 & 0.0000 & 0.0000 \\
\hline 9 & 0.0000 & 0.0000 & 0.0000 & -0.0741 & 0.0000 & 0.0000 & 0.0000 & 1.0000 \\
\hline 10 & 0.0000 & 0.0000 & 0.0000 & 0.0000 & 0.2751 & 0.2155 & 0.7472 & 0.0373 \\
\hline 11 & 0.0000 & 0.0000 & 0.0000 & 0.0000 & -0.2274 & 0.0316 & 0.7222 & 0.2462 \\
\hline
\end{tabular}

Note: In our sample maximum and minimum values are: for DEI: 0.0139 and -0.0204 , for UI: 0.0037 and -0.0033 , for UPR: 0.0025 and -0.0034 , for UTS: 0.0527 and -0.0741, for for OGREZ: 0.2751 and -0.2274 . 
Table 5 ranks annual differences between cumulative monthly abnormal returns on the smallest and largest portfolios. In some years the difference in cumulative abnormal returns between smallest and the largest stocks was negative and very large in the absolute value: 1998 (-29.96\%), 1985 (-26.94\%), $1995(-26.26 \%), 1990(-25.68 \%)$, $1989(-20.66 \%)$. On the other hand, in other years the size effect was particularly large. The highest abnormal return size differences (in our sample) were realized in 1967 (53.01\%), 1968 (37.46\%), 2002 (37.46\%), 1999 (37.27\%), $1974(33.81 \%)$. With these large differences and their cyclical trajectory (Figure 1), one might expect that there is some macroeconomic causal event, rather than just a random or year-end behavioural effect. ${ }^{14}$

To examine this issue further, we note that Bae, Karolyi, and Stulz (2003) successfully used a discrete choice model for studying extreme events in international finance. To use a similar approach to investigate large size anomaly events in the stock market, we estimate an ordered logit model, using market and macroeconomic factors as independent variables. We construct three categories for the model. Category 1 includes the lowest $10 \%$ (5 years) of the size effect. Category 3 includes highest $10 \%$ (5 years) when the size anomaly was exceptionally high. Finally, category 2 comprises the rest of the years. This model assumes that extreme return premiums may be affected differently by the independent variables than the middle-range premiums.

In this ordered Logit model, the dependent monthly variable $Y$ assumes values of the corresponding size effect categories. For example, if the year 1968 is in category 3, then every month of that year is also classified as category 3. This approach ensures that the number of observations is large, but also limits the return regimes to complete years. The ordered Logit model has the following specification:

$$
\begin{aligned}
\ln \frac{\mathrm{p}_{1}}{1-\mathrm{p}_{1}}=\alpha_{1} & +\delta_{1} \mathrm{MP}_{\mathrm{t}}+\delta_{2} \mathrm{DEI}_{\mathrm{t}}+\delta_{3} \mathrm{UI}_{\mathrm{t}}+\delta_{4} \mathrm{UPR}_{\mathrm{t}}+\delta_{5} \mathrm{UTS}_{\mathrm{t}}+\delta_{6} \mathrm{MKTREZ}_{4}+ \\
& +\delta_{16} \text { OGREZ }_{t} \\
\ln \frac{\mathrm{p}_{1}+\mathrm{p}_{2}}{1-\mathrm{p}_{1}-\mathrm{p}_{2}} & =\alpha_{2}+\delta_{1} \mathrm{MP}_{\mathrm{t}}+\delta_{2} \mathrm{DEI}_{\mathrm{t}}+\delta_{3} \mathrm{UI}_{\mathrm{t}}+\delta_{4} \mathrm{UPR}_{\mathrm{t}}+\delta_{5} \mathrm{UTS}_{\mathrm{t}}+ \\
& +\delta_{6} \text { MKTREZ }_{t}+\delta_{16} \text { OGREZ }_{t}
\end{aligned}
$$

(5c) $\mathrm{p}_{1}+\mathrm{p}_{2}+\mathrm{p}_{3}=1$

In the system of equations (4), (5), and (6), $\mathrm{p}_{1} \equiv \operatorname{Prob}(\mathrm{Y}=1), \quad \mathrm{p}_{2} \equiv \operatorname{Prob}(\mathrm{Y}=2)$, and $\mathrm{p}_{3} \equiv \operatorname{Prob}(\mathrm{Y}=3)$. The estimation attempts to classify the years by difference in abnormal returns across portfolios, assigning a "probability" of the abnormal return category based on the values of the independent variables. Maximum likelihood estimates of the model are presented in Table 6. These results suggest that macroeconomic factors are clearly related to the probabilities of observing very large or very small (negative) size effect. Estimated coefficients for macroeconomic risk factors DEI, UI, UPR, UTS, and OGREZ have coefficients that are statistically significant at $1 \%$ level.

Comparison of the significance levels of the multifactor pricing model (Table 4) and the estimates for ordered Logit (Table 6) reveals an interesting fact. In the multifactor time series model it is the orthogonalized market return MKTREZ that produces a coefficient with the largest $\mathrm{t}$-statistic. On the other hand, in the Logit model, the change in expected inflation (DEI), unexpected inflation (UI), the credit premium (UPR), term structure variable $(U T S)$, and the oil price variable (OGREZ) are highly significant. Given these different results, it appears that the macroeconomic factors influence the probable direction of the size effect, while market risk sensitivity determines the relative magnitude of the premium or the discount. This result is consistent with conditional models used in many empirical studies. For example, Ferson and Harvey (1991, 1993, 1999) and De Santis and Gerard (1998)

\footnotetext{
${ }^{14}$ Establishing a cause does not necessarily imply predictability, however.
} 
explicitly model macroeconomic variables as conditioning inputs that determine sensitivities to risk factors. ${ }^{15}$

The Logit model is specified in terms of odds ratios, which complicates interpretation of explicit relationships between the independent variables and the probabilities of observing the state of the size anomaly $\boldsymbol{Y}_{\boldsymbol{t}}=\boldsymbol{j}, \boldsymbol{j}=1,2$, or 3 . To check explicit relationships between the regressors and the dependent variable, we calculate predicted probabilities for the cases when significant regressors deviate from their means and take unusual, extreme observations. The effect of a positive (negative) deviation from the mean is obtained by substituting the maximum (minimum) value of a variable and calculating probability distribution for $\mathrm{Y}$ from the logit equation system (4), (5), and (6). $\mathrm{Y}$ is that state of a low or negative $(\mathrm{Y}=1,10 \%)$, middle range $(\mathrm{Y}=2,80 \%)$ or high $(\mathrm{Y}=3$, $10 \%$ ) size anomaly in a given year, as described for Table 5. Thus, we estimate effects of positive and negative deviations of variables, UI, UPR, UTS, and OGREZ on the probability distribution of Y, ceteris paribus, since these variables yielded statistically significant slope coefficients. All other independent variables are assumed to be at their mean values, which are all zero by construction (see Table 2).

We present results of these state-probability calculations in Table 7. If all variable were at their means of zero (line 1), then the most likely predicted outcome is $Y_{t}=2$ with $P\left(Y_{t}=2\right)=0.8105$, which means an intermediate value of the size effect. All other shifts in macroeconomic variables can be compared to this line. Consider the effect of the change in expected inflation variable (DEI) first. If there is a large increase in DEI, i.e. it is at its maximum of 0.0139 (line 2), then the predicted probability of a very large (historically highest $10 \%$ ) size effect increases from 0.1107 (base case) to 0.3341 , and the probabilities of both a negative and an average size anomaly decline. A decrease in DEI leads to an increase in the probability of the reversal in the size effect: when DEI is at its minimum of -0.0204 (line 3), the probability of $\mathrm{Y}_{\mathrm{t}}=1$ (a negative size anomaly) increases from 0.0788 (base case) to 0.3979. Similarly, an increase in UI leads to higher likelihood of $\mathrm{Y}_{\mathrm{t}}=3$ from 0.1107 to 0.1712 , and a decrease in UI is expected to increase the likelihood of $\mathrm{Y}_{\mathrm{t}}=1$ from 0.0788 to 0.1184 (line 5). The rest of the variables suggest an increase in the likelihood of a very large size effect $\left(\mathrm{Y}_{\mathrm{t}}=3\right)$ if UPR increases, and UTS or OGREZ decrease, and a significant reversal of the size effect $\left(\mathrm{Y}_{\mathrm{t}}=1\right)$ when UPR decreases and UTS or OGREZ increase.

Note that the single most important determinant of the likelihood of observing a very large or very small size effect appears to be the term structure variable UTS. If the term structure is rising sharply, i.e. UTS is at its maximum of 0.0527 (line 8), then the most likely predicted outcome is $\mathrm{Y}_{\mathrm{t}}=1$ with $\mathrm{P}\left(\mathrm{Y}_{\mathrm{t}}=1\right)=1.0000$, which is a reversal of the size effect. On the other hand, an inverted term structure (UTS at its minimum of -0.0741, line 9) is associated with the most likely predicted outcome $\mathrm{Y}_{\mathrm{t}}=3$, a very large size effect, with $\mathrm{P}\left(\mathrm{Y}_{\mathrm{t}}=3\right)=1.0000$.

One possibility is that this anomaly cycle is driven by cash flows resulting from liquidity risk. Assuming that an inverted term structure indicates a late stage bull market, possibly high inflation is expected, but market risk is low. Smaller firms should be influenced more than large firms, since they are riskier. Stock prices will respond to movements of cash toward smaller stocks with potentially higher profits, creating a very large size effect. On the other hand, when the term structure is positive, it is usual for the economy to be growing steadily with relatively low cost shorter term debt. Although smaller firms may still have higher marginal returns on investment than large firms, investors can make good returns on lower risk large firms, without taking on liquidity risk. Thus, the size effect becomes small or even reverses, as large firm profits grow steadily. ${ }^{16}$

\footnotetext{
${ }^{15}$ As a robustness check, we estimated a conditional beta model as in Ferson and Harvey (1999) with our economic risk factors, computed abnormal returns for size portfolio, and obtained results similar to presented here. Another robustness test, estimation of equation (3) using SUR or least squares method, produced consistent results. Further robustness tests split test period into two sub-periods, January 1960-December 1979, and January 1980-December 2005. The robustness tests produced similar results. Overall, the robustness checks generally confirmed our results that macroeconomic variables influence the direction of the size anomaly.

${ }^{16}$ Although this explanation is just a conjecture, several previous studies give complementary or alternative explanations for this same effect. Estrella and Hardouvelis (1991) provide evidence that that the slope of the yield curve is associated with future changes in real economic activity. Pindyck (1984), Berk et al (1999), Gomes et al (2003), and Kogan (2004) present theories linking firm-specific variables, economic conditions, and stock returns. MacKay (2003) presents empirical evidence of the crosssectional differences in leverage, debt characteristics, and production opportunities for firms of different sizes.
} 


\section{CONCLUSION}

The size anomaly has puzzled researchers since the late 1970s, since it seems to refute market efficiency or traditional asset pricing models. Recent models such as that of Fama and French (1995) seem to account for the size anomaly, but they do so by using portfolios of differences in firm size returns, and thus do not use external factors to explain the phenomenon. Hahn, O'Neil, and Reyes (2004) demonstrate that certain combinations of macroeconomic and financial variables may model the size anomaly more effectively than those of Fama and French (1995).

In this study, using time-series techniques estimation, we have also examined the ability of macroeconomic variables to supplement the market risk premium in explaining the difference between small and large firm portfolios. We used the traditional variables selected by Chen, Roll, and Ross (1986) to study their effect on the residual size anomaly after the market portfolio effect is eliminated through orthogonalization. Our initial empirical results show that macroeconomic variables do not demonstrate any strong ability to explain the residual mean size anomaly return. However, they do seem to help determine the probable direction of the anomaly.

Research beginning with Brown, Kleidon and Marsh (1983) has observed that at times the size anomaly reverses. This seems inconsistent with standard systematic risk, and most behavioural, or liquidity-based, explanations for deviation from traditional CAPM or multibeta models. But as economic conditions change, these changes may differentially alter the risks and opportunities of small and large firms. Economic conditions may change the relative risk-adjusted return potential due to firm risk characteristics and changing investor preferences for risk and return. These effects could alter the probability of large or negative size-based abnormal returns due to differing exposure across size portfolios. ${ }^{17}$

To examine this issue, our next tests related the largest and smallest (negative) size anomaly to the sample of economic variables as well as residual market systematic risk. Our results show that macroeconomic variables, not the market portfolio, provide information about whether the size effect will be low or negative, average, or exceptionally high. The strongest indicator of reversal of the size effect was the slope of the term structure. Smaller effects are attributable to inflation, the credit risk premium, and oil price changes.

These observations are consistent with a general conjecture about the return generating function or market pricing mechanism, which may partially explain this size effect phenomenon. Market participants observe macroeconomic indicators and form subjective probability distributions about the general direction of the market performance in the future. Full private information about companies is not readily available, so investors estimate required stock returns for individual companies according to their understanding of firm sensitivity to the economy. Small firms are generally more sensitive to bankruptcy and liquidity risks, which change with the state of the economy and are reflected in the term structure and credit spread. ${ }^{18}$ Exploring the question of how these variables affect small and large firm returns differentially gives possibilities for future research possibilities, although their general effect on the average market return has been studied often in the past.

Since markets are relatively efficient, investor return expectations are soon realized through trading, except for noise from unanticipated information. As new economic information is revealed, investors revise their valuation of firms based on changing anticipated cash flows and risk, weighting their investments in smaller or larger firms. However, when unusual economic conditions exist, expectations and risk preferences may change dramatically. Investment demand shifts responding to rapidly changing risks and opportunities in turn influence the likelihood of unusual size anomaly effects for different years. Thus, this study has demonstrated a potential new mechanism for macroeconomic variables to explain the occurrence and direction of a small firm anomaly.

\footnotetext{
${ }^{17}$ This type of differential exposure is consistent with various types of style investing.

${ }^{18}$ Bankruptcy and liquidity exposures are outside the assumptions of models such as the CAPM, but may be reflected both in internal exposure models, such as the mimicking portfolio returns of Fama and French (1995) and in external exposure models, such as those using macroeconomic and financial variables.
} 


\section{AUTHOR INFORMATION}

Charles E. Mossman is an Associate Professor at I. H. Asper School of Business, University of Manitoba. He is a Certified General Accountant and holds his Ph.D. in Finance from the University of Western Ontario. Professor Mossman's teaching experience is primarily in corporate finance, case teaching in finance, and small business finance. His research is mainly in financial equity markets. He is an active writer of teaching cases in finance, small business, and international business.

Sergiy Rakhmayil is an Associate Professor at Ted Rogers School of Management, Ryerson University. He holds his Ph.D. in Finance from the University of Manitoba. Professor Rakhmayil's teaching experience is in corporate finance, international finance, and personal financial planning. His research is in corporate finance, international finance, and financial equity markets.

\section{REFERENCES}

1. Al-Rjoub, Samer A. M., Oscar Varela, and M. Kabir Hassan, "The size effect reversal in the USA", Applied Financial Economics, 2005, 15, 1189-1197.

2. Athanassakos, George., "Portfolio rebalancing and the January effect in Canada", Financial Analysts Journal; Charlottesville; Nov/Dec 1992, 67-78.

3. Bae, Kee Hong, Karolyi, G. Andrew, and Rene Stulz, "An New Approach to Measuring Financial Market Contagion", Review of Financial Studies, 2003.

4. $\quad$ Banz, Rolf W., 1981, "The Relationship Between Return and Market Value of Common Stocks", Journal of Financial Economics 9, 3-18.

5. Bekaert, Geert, Eric Engstrom, and Yuhang Xing, 2009. "Risk, uncertainty, and asset prices", Journal of Financial Economics 91, 59-82.

6. Beller, Kenneth, and John R. Nofsinger "On stock return seasonality and conditional heteroskedasticity", The Journal of Financial Research, Summer 1998, 229-246.

7. Berk, Jonathan B., “A Critique of Size Related Anomalies”, The Review of Financial Studies 8-2 (1995) 275-286.

8. Berk, Jonathan B., “Does Size Really Matter?”, Financial Analysts Journal (1997) 12-18.

9. Berk, Jonathan B., Richard C. Green, and Vasant Naik, "Optimal Investment, Growth Options, and Security Returns", The Journal of Finance 54 (1999), 1553-1609.

10. Bhardwaj, Ravinder K. and Leroy D. Brooks, "The January Anomaly: Effects of Low Share Price, Transaction Costs, and Bid-Ask Bias", Journal of Finance, Vol. 47, No. 2, June 1992, 553-575.

11. Bhardwaj, Ravinder K. and Leroy D. Brooks, "Dual Betas from Bull and Bear Markets: Reversal of the Size Effect," Journal of Financial Research 16, Winter 1993, 269-283.

12. Brown, Philip, Allan W. Kleidon, and Terry A. Marsh, 1983, "New Evidence on the Nature of Size-Related Anomalies in Stock Prices", Journal of Financial Economics 12, 33-56.

13. Campbell, John Y., Lo, Andrew W., and A. Craig MacKinlay, The Econometrics of Financial Markets, Princeton University Press, Princeton, 1997.

14. Chan, K.C., Chen, Nai-Fu, and David Hsieh, "An Exploratory Investigation of the Firm Size Effect", Journal of Financial Economics 14, 1983, 451-471.

15. Chan, K.C., and Nai-Fu Chen, "An Unconditional Asset-Pricing Test and the Role of Firm Size as an Instrumental Variable for Risk", The Journal of Finance, Vol. 43, No. 2, June 1988, pp. 309-325.

16. Chan, K.C., and Nai-Fu Chen, "Structural and Return Characteristics of Small and Large Firms", The Journal of Finance, Vol. 46, No. 4. (Sept., 1991), 1467-1484.

17. Chen, Nai-Fu, Roll, Richard, and Stephen Ross, "Economic Forces and the Stock Market", Journal of Business (1986), 59, 383-403.

18. Chen, Nai-Fu, and Feng Zhang, "Risk and Return of Value Stocks," The Journal of Business 71 (1998), 501-535.

19. Cheung, Yin-Wong, and Lilian K. Ng, "Stock Price Dynamics and Firm Size: An Empirical Investigation", The Journal of Finance, Vol. 47, No. 5 (Dec., 1992), 1985-1997.

20. Cho, D. Chinhyung, and William M. Taylor, "The Seasonal Stability of the Factor Structure of Stock Returns", The Journal of Finance, Vol. 42, No. 5. (Dec., 1987), 1195-1211. 
21. De Santis, Giorgio, and Bruno Gerard, "How big is the premium for currency risk", Journal of Financial Economics 49 (1998): 375-412.

22. Dimson, Elroy, "Risk Measurement when Shares Are Subject to Infrequent Trading", Journal of Financial Economics 7, 1979, 197-226.

23. Dimson, Elroy and Paul Marsh, "Murphy's Law and market anomalies", Journal of Portfolio Management, Winter 1999, 53-69.

24. Eckbo, B. Espen, Ronald Masulis, and Oyvind Norli, "Seasoned Public Offerings: Resolution of the 'New Issues Puzzle'," Journal of Financial Economics 56 (2000), 251-291.

25. Estrella, Arturo, and Gikas A. Hardouvelis, "The Term Structure as a Predictor of Real Economic Activity”, The Journal of Finance, Vol. 46, No. 2. June 1991, pp. 555-576.

26. Fama, Eugene F. and Michael R. Gibbons, “A comparison of Inflation Forecasts”, Journal of Monetary Economics 13 (1984), 327-348.

27. Fama, Eugene F., and Kenneth R. French, "The Cross-Section of Expected Stock Returns", Journal of Finance 47 (1992): 427-465.

28. Fama, Eugene F. and Kenneth R. French, "Size and Book to Market Factors in Earnings and Returns", Journal of Finance 50, Issue 1 (1995): 131-155.

29. Ferson, Wayne E., and Campbell R. Harvey, "The variation of economic risk premiums", Journal of Political Economy 99, Issue 2 (1991): 385-415.

30. Ferson, Wayne E., and Campbell H. Harvey, "The risk and predictability of international equity returns", Review of Financial Studies 6, Issue 3 (1993): 527-566.

31. Ferson, Wayne E., and Campbell R. Harvey, "Conditioning variables and the cross-section of stocks returns", Journal of Finance 54, Issue 4 (1999): 1325-1360.

32. Gomes, Joao, Leonid Kogan, and Lu Zhang, "Equilibrium Cross Section of Returns", The Journal of Political Economy 111 (2003), 693-732.

33. Goyal, Amit , and Pedro Santa-Clara, 2003. "Idiosyncratic Risk Matters!” The Journal of Finance. 58, 9751007.

34. Greene, William H., Econometric Analysis, $4^{\text {th }}$ Edition, Prentice Hall, Upper Saddle River (2000).

35. Hahn, TeWhan, Michele O'Neil, and Mario G. Reyes, "Anomalies: Is It the Economy? The Journal of Financial Research 27 (2004), 273-287.

36. Kogan, Leonid, "Asset prices and real investment", Journal of Financial Economics 73 (2004), 411-431.

37. Keim, Donald B., "Size Related Anomalies and Stock Return Seasonality: Further Empirical Evidence", Journal of Financial Economics, 1983, 12, 13-32.

38. Kramer, Charles, "Macroeconomic Seasonality and the January Effect", The Journal of Finance, Vol. 49, No. 5, Dec. 1994, pp. 1883-1891.

39. MacKay, Peter, "Real Flexibility and Financial Structure: An Empirical Analysis", The Review of Financial Studies 16, 2003, 1131-1165.

40. Mehdian, Seyed, and Mark J. Percy, "Anomalies in US equity markets: A reexamination of the January effect ", Applied Financial Economics, Feb 2002, 141-145.

41. Mei, Jianping, "Explaining the cross section of returns via a multi-factor APT model", Journal of Financial and Quantitative Analysis; Seattle; Sep 1993, 331-345.

42. Moskowitz, Tobias J. 2003. An Analysis of Covariance Risk and Pricing Anomalies, Review of Financial Studies 16, 417-457.

43. Olson, Dennis, Mossman, Charles, and Nang-Ting Chou, "Is there a Life Cycle for Seasonal Stock Market Anomalies?" Unpublished manuscript at the American University of Sharjah, September 2002..

44. Pindyck, Robert S., "Risk, Inflation, and the Stock Market", The American Economic Review 74 (1984), 335-351.

45. Reinganum, Marc R., "Misspecification of Capital Asset Pricing: Empirical Anomalies Based on Earnings' Yields and Market Values", Journal of Financial Economics 9, 1981, 19-46.

46. Reinganum, Marc. R., "The Anomalous Stock Market Behavior of Small Firms in January: Empirical Tests for Tax Loss Selling Effects", Journal of Financial Economics 12, 1983, 89-104.

47. Ross, Stephen A., "The Arbitrage Theory of Capital Asset Pricing”, Journal of Economic Theory, 1976, 13, 341-360.

48. $\quad$ Rozeff and Kinney, "Capital Market Seasonality: The Case of Stock Returns," Journal of Financial Economics 3, 1976, 379-402. 
49. Seyhun, H. Nejat, "Can Omitted Risk Factors Explain the January Effect? A Stochastic Dominance Approach", The Journal of Financial and Quantitative Analysis, Vol. 28, No. 2. (Jun., 1993), pp. 195212.

50. Theriou, Nikolaos G, Dimitrios I Maditinos, Prodromos Chadzoglou, and Vassilios Anggelidis, "The Cross-Section of Expected Stock Returns: An Empirical Study in the Athens Stock Exchange", Managerial Finance 31, 2005, 58-79. 


\section{NOTES}

